\title{
ARTICLE
}

\section{Flexible heat-resistant neutron and gamma-ray shielding resins}

\author{
Atsuhiko M. Sukegawa ${ }^{\mathrm{a}^{*}}$ and Yoshimasa Anayama \\ ${ }^{a} J a p a n$ Atomic Energy Agency, 801-1 Mukoyama, Naka-shi, Ibaraki-ken, 311-0193, Japan; ${ }^{b}$ Neotec-R\&D, 6-6-1 Ginza,Chuo-ku, \\ Tokyo-to, 104-0061, Japan
}

\begin{abstract}
Flexible heat-resistant neutron and gamma-ray shielding resins have been successfully developed through the use of a polymer resin. The production process involves a new mixing technique of the resin and materials for neutron absorber/gamma-ray attenuation using a new cold-setting method. The process allows for easy onsite fabrication. The materials are $\mathrm{B}_{4} \mathrm{C}$ powder for neutron shield, Colemanite powder for neutron/gamma-ray shield and FeW powder for gamma-ray shield, respectively. We assessed a basic property and neutron penetration performance of the neutron/gamma-ray shielding resin and carried out a neutron irradiation test of the resin using Japan Research Reactor 3. Gamma-ray shielding performance of the developed resin with FeW powder was performed by using a Monte-Carlo calculation code. The neutron and gamma-ray shielding resins can be used in a high-temperature environment $\left(\sim 200^{\circ} \mathrm{C}\right)$. These resins will be applied around tokamak fusion devices as an additional shielding: they can reduce neutron and gamma-ray streaming from the device.
\end{abstract}

\section{Keywords: flexible; heat-resistant; neutron shielding; gamma-ray shielding; resin; durability;} radiation-resistant; JRR-3

\section{Introduction}

In high-temperature environments, such as those of tokamak fusion devices, suitable neutron and gamma-ray shielding is required. The temperature around the vacuum vessel of tokamak fusion devices for plasma confinement is $\sim 200{ }^{\circ} \mathrm{C}$ because wall conditioning by baking of the vacuum vessel removes $\mathrm{H}_{2} \mathrm{O}, \mathrm{O}_{2}, \mathrm{CH}_{2}$, and $\mathrm{CH}_{4}$. Pure water is generally used for neutron shielding in the vacuum vessel; the shielding structure consists of a double wall filled with water to confine fusion plasmas. Many ports are attached to the vessel for plasma heating and diagnostics. However, it is difficult to shield against the fusion neutrons by water. Nuclear heating can be effectively reduced by shielding against fusion neutrons using a thermosetting resin.

As the resin shields against neutrons and gamma rays are flexible in shape and light in weight, it can be installed near the devices as a shock absorber for the collimator of the diagnostics.

Polyethylene is effective and the most popular resin for neutron shielding; however, its heatproof temperature is fairly low. Concrete is effective for neutron and gamma ray shielding and can endure high temperatures, but it is not suitable for additional shielding in narrow and restricted spaces such as the tokamak fusion device. Lead is an effective gamma-ray

*Corresponding author. Email: morioka.atsuhiko@jaea.go.jp shield, but it is unsuitable for use in a high-temperature environment.

Heatproof neutron-shielding resins were developed, such as Krafton-HB4 in 1994 [1] and Eponite in 2004 [2]. Krafton-HB4 is an epoxy-based resin that contains boron to reduce low energy neutrons. It was developed as a future shielding material for fast breeder reactors. Eponite is an epoxy-based resin based on Colemanite(a natural rock that contains boron). Its heat-resistant temperature is less than $180{ }^{\circ} \mathrm{C}$. We required a neutron-shielding resin with higher heatproof temperature. A boron-loaded neutron-shielding resin with heat resistance of $300{ }^{\circ} \mathrm{C}\left(300{ }^{\circ} \mathrm{C}\right.$ resin) was developed in 2005 [3]. The heat-resistant performance has gradually been improved. The shielding performance of these resins was assessed [4]. Thermosetting resins are required in a high-temperature environment. The $300{ }^{\circ} \mathrm{C}$ resin is made by a hot-press setting method in a factory; a press machine is necessary for manufacture. Thus, onsite fabrication of the $300{ }^{\circ} \mathrm{C}$ resin is difficult.

Recently, R\&D of gel-type heat-resistant resins has been initiated in response to the need for more flexible and lightweight shielding materials; these are expected to be useful in situations where additional shielding is required in narrow and restricted spaces or hard-to-reach areas such as collimators for diagnostics [5]. A flexible heat-resistant resin was developed to overcome the fabrication methods using the previous resins. 
In this study, new, flexible, and heat-resistant neutron and gamma-ray shielding materials are developed to act as sealing material around ports in a tokamak fusion device to prevent radiation streaming. In this paper, the production methods by a new cold-setting method and the characteristics of the newly developed shielding resins are introduced.

\section{Production method}

\subsection{Material choice}

A flexible heat-resistant neutron shielding resin was developed based on Krafton-HB4. Most produced heat-resistant resins are not flexible and use an amide-polymer resin. We improved the matrix of the amide-polymer resin. For the hardener, a fatty acid ester resin with radiation resistance was selected. A polymer resin with a new chemical structure was developed by optimization of the base material and hardener to improve the heat-proofing. Figure 1 shows typical neutron and gamma-ray shielding materials. $\mathrm{B}_{4} \mathrm{C}$, Colemanite and $\mathrm{FeW}$ were selected as low-cost shielding materials against neutrons, neutrons and gamma rays, and gamma rays, respectively.

\begin{tabular}{|c|c|c|}
\hline $\begin{array}{l}\mathrm{B}_{4} \mathrm{C} \\
\mathrm{Gd} \\
\mathrm{Sm} \\
\mathrm{Eu} \\
\mathrm{Cd} \\
\mathrm{Dy} \\
\mathrm{B} \\
\mathrm{ZrH}_{2} \\
\mathrm{TiH}_{2} \\
\mathrm{LiH}_{3} \\
\mathrm{H}_{3} \mathrm{BO}_{3}\end{array}$ & $\begin{array}{l}\text { Colemanite } \\
\text { Concrete } \\
\text { Heavy Weight } \\
\text { Concrete } \\
\text { Fe }\end{array}$ & $\begin{array}{l}\text { FeW } \\
\text { Lead } \\
\text { W } \\
\text { Glass } \\
\text { Pb-Glass }\end{array}$ \\
\hline
\end{tabular}

Figure 1. Neutron and gamma-ray shielding materials.

\subsection{Trial products}

We mixed a developed base resin, hardener, and shield material at a cold setting. The setting temperature was about $20 \pm 15{ }^{\circ} \mathrm{C}$. It is important to keep the resin, hardener and shielding material uniform in the mixture technique. The resins and shielding material are usually separated before preliminary hardening of the base resin. In order to prevent separation, the previous heat-resistant neutron shielding resin was manufactured by using supersonic waves. However, this fabrication method requires a special horn. In addition, this makes onsite fabrication in narrow spaces difficult. Thus, we developed a remedy to simplify the manufacturing process. We developed a new agitation technique that uses only a chemical reaction to produce an improved flexible, heat-resistant, and radiation-shielding resin. Figure 2 shows the uniformity of $\mathrm{FeW}$ powders using the new mixture technique.

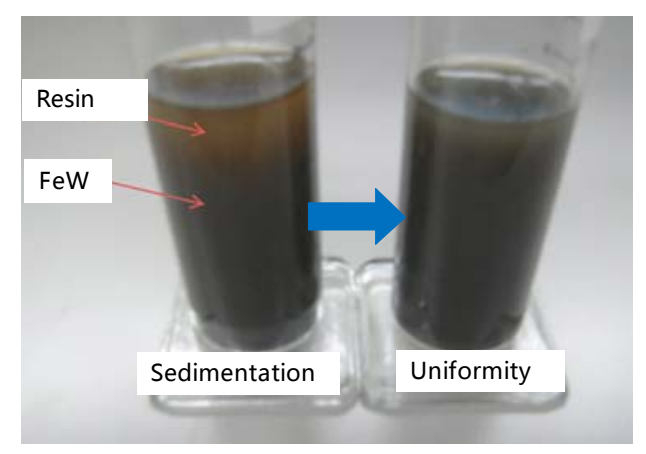

Figure 2. Sedimentation of FeW powder $\left(\rho=10.2 \mathrm{~g} / \mathrm{cm}^{3}\right)$ and uniformity of FeW powder by a newly mixture technique.

\subsection{Developed flexible heat-resistant resins}

Figure 3 shows the flexible heat-resistant neutron, neutron/gamma-ray and gamma-ray shielding resins developed using this technique. The white-type resin on the left side uses Colemanite powder for neutron and gamma-ray shielding; the black-type resin in the center uses $\mathrm{B}_{4} \mathrm{C}$ powder for neutron shielding; and the black-type resin on the right side uses FeW powder for gamma-ray shielding.

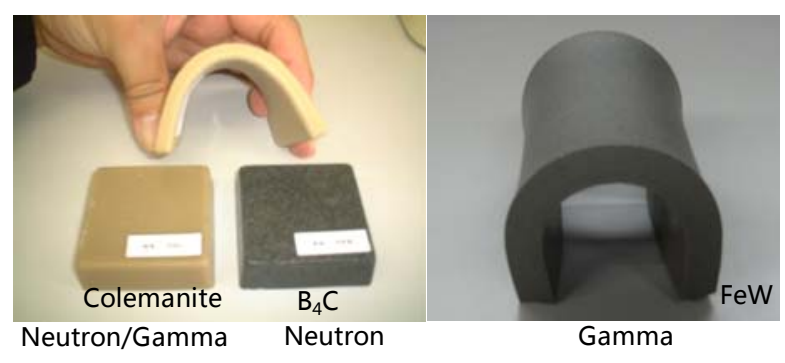

Figure 3. Developed flexible heat-resistant resins.

\section{Characteristics of developed flexible resin with Colemanite}

\subsection{Basic property}

Table 1 lists the main chemical components of the developed resin with Colemanite for neutron/gamma shielding. The measured density of the resin was 1.28 $\mathrm{g} / \mathrm{cm}^{3}$. The compositions and densities of the other two resins have not been measured yet. The resin offers the

Table 1. Chemical composition of the developed resin.

\begin{tabular}{cc}
\hline Component & $\begin{array}{c}\text { Weight } \\
(\mathrm{wt} \%)\end{array}$ \\
\hline C & 46.8 \\
$\mathrm{~N}$ & 2.2 \\
$\mathrm{O}$ & 27.6 \\
$\mathrm{H}$ & 8.21 \\
$\mathrm{~B}$ & 3.4 \\
Other & 11.8 \\
\hline
\end{tabular}


following advantages: it can be used at temperatures up to $200{ }^{\circ} \mathrm{C}$; it is flexible and heat resistant; its production is easier compared with the supersonic wave method; and onsite fabrication with a cold-setting method.

\subsection{Heatproof temperature}

To examine the heat-proof performance of the developed resins, thermogravimetric(TG)/differential thermal analysis (DTA) was used. DTA was carried out by heating the specimen of the developed resin together with a reference standard under identical thermal conditions in the same oven and measuring the temperature difference between the specimen and reference substance during the period of heating. The temperature was increased from $20{ }^{\circ} \mathrm{C}$ to $320{ }^{\circ} \mathrm{C}$ at a rate of $10^{\circ} \mathrm{C} / \mathrm{min}$. Nitrogen was used as the purge gas. The weight of the developed resin decreased by $1 \%$, $5.0 \%$ and $10.0 \%$ at 226.8, 285.5, and $312.0{ }^{\circ} \mathrm{C}$, respectively. The decomposition temperature is the point where the asymptote of the resolution beginning point $\left(226.8{ }^{\circ} \mathrm{C}\right.$ ) intersects with the asymptote of the $5 \%$ decomposition lost point $\left(285.5^{\circ} \mathrm{C}\right)$. The temperature at which the chemical compound was resolved into its constituent elements was $271.1^{\circ} \mathrm{C}$. The resin should not be used over $271.1{ }^{\circ} \mathrm{C}$ due to carry out a phase transition of this resin.

\section{Neutron irradiation experiments for developed flexible resin with Colemanite}

\subsection{Neutron shielding performance using ${ }^{252} \mathrm{Cf}$ source}

The neutron shielding characteristics of a $40 \times 40 \times 5$ $\mathrm{cm}^{3}$ sample of the developed resin with Colemanite was examined by a neutron penetration experiment with a ${ }^{252} \mathrm{Cf}$ neutron source (average energy of the neutron source: $2.3 \mathrm{MeV})$ at room temperature $\left(\sim 20{ }^{\circ} \mathrm{C}\right)$. The neutron dose rate was measured with a neutron REM counter. The neutron dose rate was also calculated with the nuclear data library JENDL-3.3 [6] and the 3D Monte Carlo code MCNP-5 [7]. The measured and calculated neutron dose rate distributions in the developed resin normalized at the thickness of $0 \mathrm{~cm}$ are shown in Figure $\mathbf{4}$ as a function of the thickness with the calculated one in polyethylene. The calculation result

with FSD value of less than $5 \%$ agrees with the measured one. The neutron shielding performance of the resin is almost the same as that of polyethylene.

\subsection{Radiation durability using research reactor}

The neutron durability characteristics of the developed neutron shielding resin were evaluated on the test pieces ( $10 \mathrm{mg}$ ) by using the pneumatic system (PN-1) of Japan Research Reactor 3 (JRR-3). Figure 5 shows the arrangement of irradiation holes in JRR-3. The inside diameter of the capsule for $\mathrm{PN}-1$ is $\phi 2.35 \mathrm{~cm}$ $\times 7.2 \mathrm{~cm}$. Under the neutron irradiation condition, the irradiation time was $20 \mathrm{sec}$. The total neutron fluence of

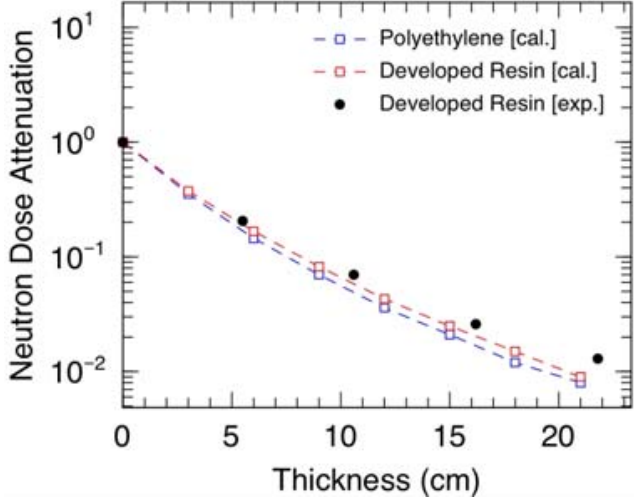

Figure 4. Neutron shielding performance.

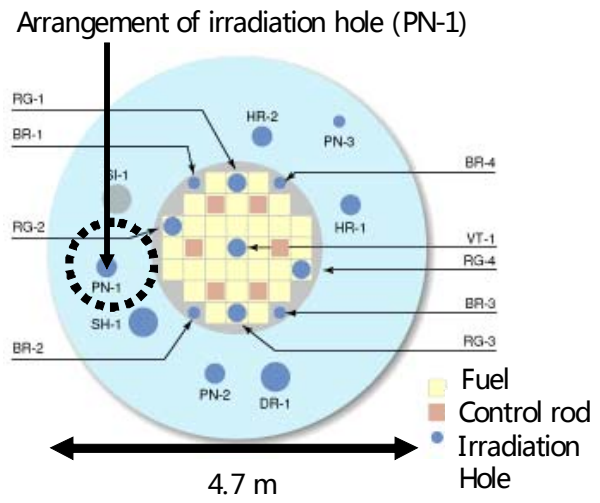

Figure 5. Arrangement of irradiation hole in JRR-3.

PN-1 was estimated by $1 \mathrm{D}$ analysis to be $7.5 \times 10^{15}$ $\mathrm{n} / \mathrm{cm}^{2}$. Most of the neutron fluence was thermal neutrons according to the neutron spectrum of $\mathrm{PN}-1$. Weight reduction of the test piece after irradiation at $\mathrm{PN}-1$ was not observed. The total nuclear heating of the resin in PN-1 was estimated to be $256 \mathrm{~W} / \mathrm{cc}$. The resin temperature in $\mathrm{PN}-1$ was evaluated using the measured specific heat capacity of the developed resin. The temperature was estimated to be $\sim 66{ }^{\circ} \mathrm{C}$. Most of the nuclear heating came from the ${ }^{10} \mathrm{~B}(\mathrm{n}, \alpha)$ reaction of the thermal neutrons.

In a superconducting fusion tokamak device [8], resin will be installed around the port section. The thermal neutron flux level at the port section was estimated by $3.35 \times 10^{10} \mathrm{n} / \mathrm{cm}^{2}$ at 10 -year operation. So, the developed resin with Colemanite is found to be applicable in tokamak fusion devices.

\section{Simulations for gamma-ray shielding performance of developed flexible resin with FeW}

We got a flexible heat-resistant gamma-ray shielding resin as shown in Fig. 3. FeW powder could be mixed into the resin up to a ratio of about $50 \%$ with flexibility.

Tokamak DD fusion device (DD neutron : $2.45 \mathrm{MeV}$ ) such as JT-60SA which will be developed under the 
project Europe and Japan is fabricated from many stainless steels [8]. The annual neutron yields of JT-60SA will increase by about fifty times the permitted amount of neutron yields in the existing JT-60 device. ${ }^{60} \mathrm{Co}$ from the ${ }^{59} \mathrm{Co}(\mathrm{n}, \gamma)$ reaction in the stainless steels are a main gamma-ray source [9]. It is necessary to reduce the worker's exposed dose for the maintenance of the device. Therefore, we have assessed the gamma-ray shielding performance of the developed flexible resin with FeW using 3D radiation transport code.

The shielding performance of the resin against gamma-rays from ${ }^{60} \mathrm{Co}(\mathrm{E} \gamma=1.17 \mathrm{MeV}$ and $1.33 \mathrm{MeV})$ was estimated under the same condition as the neutron shielding experiment. Figure 6 shows the estimated results with FSD value of less than $5 \%$ of the gamma-ray shielding performance using MCNP5 with the chemical composition of a polymer resin and FeW. The figure shows the photon dose for FeW $0 \%$ ( black line: $1.17 \mathrm{MeV}$, black dot line: $1.33 \mathrm{MeV}$ ), FeW 50\% ( red line: $1.17 \mathrm{MeV}$, red dot line: $1.33 \mathrm{MeV}$ ) and FeW $100 \%$ ( blue line: $1.17 \mathrm{MeV}$, blue dot line: $1.33 \mathrm{MeV}$ ). Although the amount of combination of a flexible polymer resin and FeW powder needs to be optimized, a flexible gamma-ray shielding resin with $\mathrm{FeW} 50 \%$ will become an attractive material in respect of cost.

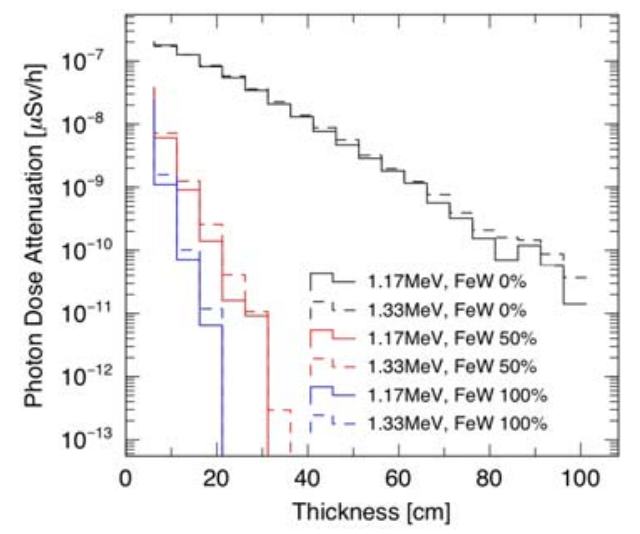

Figure 6. Gamma-ray shielding performance $(\mathrm{E} \gamma=1.17 \mathrm{MeV}$ and $1.33 \mathrm{MeV}$ ).

\section{Conclusion}

In this R\&D study, attractive gel-type radiation shielding resins were developed with improved heatproofing.

Its features are summarized as follows.

- The neutron shielding performance of the neutron/gamma-ray shielding resin with Colemanite is almost the same as that of the polyethylene as measured with a ${ }^{252} \mathrm{Cf}$ neutron source.

- The weight of the neutron/gamma-ray shielding resin with Colemanite does not change at the thermal neutron fluence of $7.5 \times 10^{15} \mathrm{n} / \mathrm{cm}^{2}$ using the research reactor.

- The gamma-ray shielding performance of the developed gamma-ray shielding resin with $\mathrm{FeW}$ by ${ }^{60} \mathrm{Co}$ source is high.

\section{Acknowledgements}

We would like to acknowledge S. Ohnishi and M. Asami (National Maritime Research Institute) for the neutron transmission experiment.

Present study includes the result of "Research and Development for High Heat Resistant of Gel-type Neutron Shielding Resin” entrusted to Japan Atomic Energy Agency by MEXT.

\section{References}

[1] K. Ueki. A. Ohashi, N. Nariyama, S. Nagayama, T. Fujita, K. Hattroi and Y. Anayama, Systematic evaluation of neutron shielding effects for materials, Nuclear Science and Engineering 124 (1996), pp.455-464.

[2] K. Okuno, Neutron shielding material based on colemanite and epoxy resin, Radiation Protection Dosimetry 115 (2005), pp.258-261.

[3] A. Morioka, S. Sakurai, K. Okuno, S. Sato, Y. Verzirov, A. Kaminaga, T. Nishitani, H. Tamai, Y. Kudo, S. Yoshida and M. Matsukawa, Development of $300^{\circ} \mathrm{C}$ heat resistant boron-loaded resin for neutron shielding, Journal of Nuclear Materials 367-370 (2007), pp.1085-1089.

[4] A. M. Sukegawa, S. Sakurai, K. Okuno, S. Sato, Y. Verzirov, A. Kaminaga, T. Nishitani, H. Tamai, Y. Kudo, S. Yoshida and M. Matsukawa, High heat resistant neutron shielding resin, Nuclear Technology 168 (2009), pp.553-558.

[5] A. M. Sukegawa, Y. Anayama, S. Ohnishi, S. Sakurai, A. Kaminaga and K. Okuno, Development of flexible neutron-shielding resin as an additional shielding material, Journal of Nuclear Science and Technology 48 (2011), pp.585-590.

[6] K. Kosako, N. Yamano, T. Fukahori, K. Shibata and A. Hasegawa, The Libraries Fsxlib and Matxslib Based on JENDL-3.3, JAERI-Data/Code 2003-011, Japan Atomic Energy Research Institute, (2003).

[7] X-5 Monte Carlo Team, MCNP-A General Monte Carlo N-Particle Transport Code, Version 5, Los Alamos National Laboratory, (2003).

[8] A. M. Sukegawa, H. Kawasaki and K. Okuno, Conceptual radiation shielding design of superconduction tokamak fusion device by PHITS, Prog. Nuclear Science and Technology 2 (2011), pp.375-381.

[9] A. M. Sukegawa, N. Miya and A. Oikawa, Management of radioactive materials for the disassembly of JT-60U fusion tokamak device, Proc. 19th Inter. Conf. on Nuclear Engineering (ICONE19th), May, 2011, Chiba, Japan, (2011). ISBN 978-4-88898-204-7. [CD-ROM] 